\title{
Numerical Investigation of the Dynamic Performance and Riding Comfort of a Straddle-Type Monorail Subjected to Moving Trains
}

\author{
Qingfei Gao ${ }^{1, *}$, Kemeng Cui ${ }^{2}$, Zhonglong $\mathrm{Li}^{1}$ and $\mathrm{Yan} \mathrm{Li}^{1}$ \\ 1 School of Transportation Science and Engineering, Harbin Institute of Technology, Harbin 150090, China; \\ lizhonglong@hit.edu.cn (Z.L.); liyan2011@hit.edu.cn (Y.L.) \\ 2 School of Civil Engineering, Southeast University, Nanjing 210096, China; cuikemeng@seu.edu.cn \\ * Correspondence: gaoqingfei@hit.edu.cn; Tel.: +86-137-0361-6436
}

Received: 26 June 2020; Accepted: 27 July 2020; Published: 30 July 2020

check for updates

\begin{abstract}
The driving comfort of a straddle-type monorail, while considering the influence of the bridge structure, was studied on the basis of multibody dynamics and the finite element method. In this study, the coupled vehicle-bridge model was established through SIMPACK and ANSYS; the 3D model of the bridge was established in ANSYS, and the vehicle model with 35 degrees of freedom (DOFs) was established in SIMPACK. The influence of the vehicle speed, pier height, track irregularity, and vehicle load on riding comfort was studied. Overall, straddle-type monorails had a good running stability, and the lateral comfort of the vehicle was better than the vertical comfort, due to symmetrical horizontal wheels. As the vehicle speed increased, the acceleration of the bridge and vehicle increased accordingly. Track irregularity had a substantial influence on riding comfort. Three types of track irregularity were simulated, and this factor should be strictly controlled to be smoother than the Chinese national A-level road roughness. The bridge pier height had a notable influence on the lateral riding comfort. In addition, this study attempted to improve riding comfort from the perspective of increasing the bridge stiffness, which could be achieved by increasing the cross-beam thickness or the track beam height.
\end{abstract}

Keywords: straddle-type monorail; vehicle-bridge coupling vibration; riding comfort; dynamic response

\section{Introduction}

Rail transit has become a lifeline of urban transportation and is characterized by fast speeds, large traffic volumes, good ride environments, and short operation delays [1]. Straddle-type monorails are a new form of rail transit that requires a small floor space, a short construction period, and exhibits good topographic adaptability [2-5]. There are concrete or steel track beams instead of steel rails in a straddle-type monorail, and these beams not only bear vehicle loads but also serve as guiding tracks. The straddle-type monorail vehicle has three types of rubber wheels that are called the walking wheel, the guiding wheel, and the stability wheel [6], which directly contact the track beam. Many cities in China have either used this form of transportation or have included it in traffic planning. To meet passenger requirements for travel comfort, it is necessary to analyze the vehicle-bridge coupling vibrations and study the riding comfort of straddle-type monorails. Most current dynamic analysis approaches and riding comfort studies for rail transit involve railways. However, the wheel-rail contact mechanism of straddle-type monorails is rubber wheel-road contact, which is quite different from the contact mechanism in traditional rail transit.

Vehicle-bridge coupling vibration is a complex dynamic problem that involves vehicle mechanics, bridge supports, vehicle speed, and track or road irregularities. Chu et al. [7-9] proposed a vehicle 
model for studying vehicle-bridge coupling vibrations, wherein the model had 11 degrees of freedom (DOFs) and considered only vertical vibrations. Wang et al. [10-12] studied the spatial vibration response of a train passing through a simply supported truss bridge, by using separate vehicle-bridge motion equations and considering irregular excitations. Vanbogaert [13] investigated the dynamic response of a train passing through an arch bridge and calculated the impact coefficient, which could reflect the influence of a vehicle load on the dynamic performance of a bridge. Another noteworthy contribution was made by Eom and Lee [14], who studied the running safety of trains passing through curves and defined a relationship between the derailing coefficient, the load reduction rate, the curve radius, and the track slope. Miyamoto et al. $[15,16]$ considered earthquake events when analyzing the coupling response and the riding comfort of a train-bridge system. Fryba [17] focused on the resonance phenomenon between a train and a bridge and proposed a simple expression of the dynamic amplification coefficient. Lee et al. [18] made a great contribution to establish the motion equation of a coupled vehicle-bridge system based on the Lagrange equation, and then studied the influence of vehicle speed and load on vehicle-bridge coupling vibrations. Their results showed that the lateral dynamic response of the bridge was positively correlated with vehicle speed but negatively correlated with load. Naeimi [19] proposed a train-track beam interaction model based on multibody dynamics and finite element (FE) simulations, and studied the effect of train motion on the dynamic responses of bridge structures. The track beam was numerically simulated with flexible elements, and the monorail vehicle was simulated with the multibody software MSC Adams. In the field of highway traffic, Yang [20] presented a parametric analysis on vehicle riding comfort, wherein the influences of track irregularity, bogie stiffness, suspension system damping, and other factors were considered. Carlbom [21] suggested that a bogie could be simulated as a multibody model and that a car body could be simulated as an FE model; moreover, they established the motion equation for the flexible multibody model, while considering track irregularity. Zhang [22] detected the damage of highway bridges under the action of vehicle loads, with strain monitoring data. Gao $[23,24]$ simulated and analyzed the dynamic characteristics of the highway vehicle-bridge coupling system based on ANSYS.

Several studies on the dynamic behavior of monorail traffic were carried out based on the above research results. Yildiz and Sivrioglu [25] proposed a method to study the dynamic responses of straddle-type monorail trains, under the action of transverse winds, and used shock absorbers to control the lateral and rolling motion of the vehicle. Ivanchenko [26] proposed a substructure method to study the dynamic responses of monorails during high-speed operation. The vehicles were regarded as a moving substructure comprising rod elements, whereas the bridge was regarded as rigid bodies with viscoelastic links. Hence, the complex equations of motion of the system were replaced by those of two simple substructures. Rybak [27] established a monorail-bridge-foundation system model to assess the vibration characteristics of the monorail system. However, the motion equation of the vehicle was complicated, and the motion equation of the elastic monorail-bridge system was difficult to solve due to the particular structure of straddle-type monorails. The vehicle in a straddle-type monorail is a typical multi-rigid body structure. Therefore, a method based on multibody dynamics was developed to study the dynamic behavior of straddle-type monorail-bridge systems.

Goda [28-30] established the motion equation of a straddle-type monorail vehicle through multibody dynamics and studied its curve passing performance, without considering the deformation of the track beam. Zheng et al. [31,32] established a straddle-type monorail vehicle model with the multibody software SIMPACK, analyzed the dynamic response of the vehicle in curve driving, and proposed a reasonable curve driving speed. However, supporting structures or bridges of monorail traffic were ignored. Shi et al. [33] conducted a dynamic test on the typical sections of the Chongqing straddle-type monorail, during which they tested the strain, displacement, and acceleration of the track beam under different speeds and braking conditions, thereby, providing a database for follow-up studies on the dynamic behavior of straddle-type monorails. Bao et al. [34] established a monorail suspension model with SIMPACK and carried out dynamic analysis of the coupled vehicle-bridge system, through which they studied the influence of factors, such as speed and track irregularity, on 
the dynamic characteristics of the coupled system. Qiao [35] carried out dynamic simulations on straddle-type monorail vehicle-bridge coupled systems, and proposed improved design parameters for the track beam. Several scholars made substantial efforts to solve the problem of vehicle-bridge coupling vibrations in straddle-type monorails, based on the multibody dynamic theory. However, although the supporting bridge of a monorail is a typical elastic structure, it is still necessary to explore a suitable method to study vehicle-bridge coupling vibrations, based on the characteristics of straddle-type monorails and bridges. In this study, a combined method based on FE theory and multibody dynamics was proposed, which accounted for the dynamic characteristics of the vehicle and the bridge.

In this study, a coupled vehicle-bridge model was proposed, based on FE theory and multibody dynamics. The FE method was used to establish an elastic bridge model, whereas the multibody dynamics theory was used to establish a vehicle model. These were combined by the coordination of wheel-rail contact points. Taking the bridge dynamic response and vehicle dynamic response as the main indices, the influence laws of the vehicle speed, pier height, vehicle load, and track irregularity, on the dynamic performance and riding comfort of straddle-type monorails were studied. Finally, measures to improve the riding comfort of straddle-type monorails were proposed, which could provide some basis for designing similar projects.

\section{Coupled Straddle-Type Monorail-Train System}

The coupled straddle-type monorail-bridge system was simulated based on the multibody dynamics method and the FE method. First, the straddle-type monorail model was established in SIMPACK - multibody dynamics software-and then the monorail train model was assembled by monorail models. A simply supported track beam bridge model was established by ANSYS, which is an FE analysis software program. Finally, the coupling of the monorail and bridge was finished in SIMPACK, while considering track irregularity.

\subsection{Straddle-Type Monorail Model}

A straddle-type monorail train consists of two bogies and a vehicle body. Each bogie is composed of a bogie frame, rubber wheels, a suspension system, and a braking system. There are three types of rubber wheels-walking wheels, which provide movement and bear most of the vertical force; stabilizing wheels, which are installed on each side of the bogie to maintain vehicle balance and prevent vehicle roll; and guiding wheels, which play an important role in guiding the direction of the vehicle, especially when passing curves. The suspension system acts as a force transmission and vibration attenuation device and consists of two air springs, two shock absorbers, and a traction rubber pile. The dynamics analysis model of a straddle-type monorail vehicle is shown in Figure 1.

Rigid bodies are used to simulate the vehicle body, bogies, and wheels in SIMPACK, the mechanical characteristics of the suspension system are simulated by force elements, and the elastic characteristics of the rubber wheels are simulated by the tire elements. The DOFs of the vehicle model are defined by hinges and constraints. In this study, six rigid body DOFs, which are described as longitudinal, vertical and lateral translation, rolling, pitching, and yawing, were considered for the vehicle body and the bogies, and one rotation freedom was considered for each rubber tire. Thus, the monorail vehicle model had 38 DOFs, as shown in Table 1. 


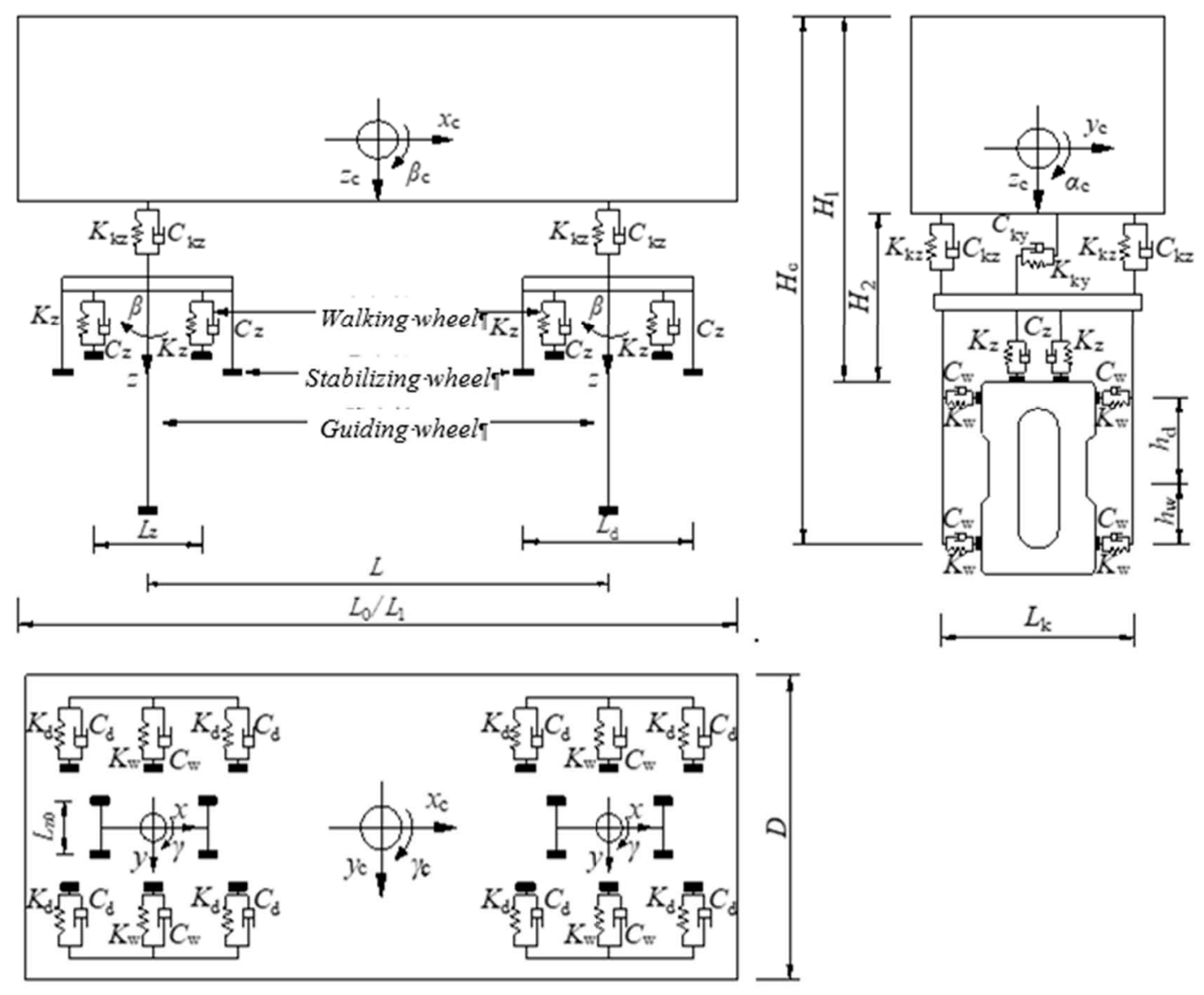

Figure 1. Dynamics analysis model of a straddle-type monorail.

Table 1. Degrees of Freedom (DOFs) of a straddle-type monorail vehicle.

\begin{tabular}{ccccccc}
\hline Components & $\begin{array}{c}\text { Longitudinal } \\
\text { Translation } \\
x\end{array}$ & $\begin{array}{c}\text { Vertical } \\
\text { Translation } \\
y\end{array}$ & $\begin{array}{c}\text { Lateral } \\
\text { Translation } \\
z\end{array}$ & $\begin{array}{c}\text { Rolling } \\
\alpha\end{array}$ & $\begin{array}{c}\text { Pitching } \\
\beta\end{array}$ & $\begin{array}{c}\text { Yawing } \\
\gamma\end{array}$ \\
\hline Vehicle body and bogies & $\sqrt{ }$ & $\sqrt{ }$ & $\sqrt{ }$ & $\sqrt{ }$ & $\sqrt{ }$ & $\sqrt{ }$ \\
Walking wheels & - & - & - & - & - & $\sqrt{ }$ \\
Guiding wheels & - & - & - & - & - & $\sqrt{ }$ \\
Stabilizing wheels & - & - & & - & - & \\
\hline
\end{tabular}

A topology graph that clearly describes the relationship between the various components of the monorail vehicle was introduced as the modeling basis, which was convenient for model troubleshooting. The topology graph of a straddle-type monorail is presented in Figure 2. The tire was adopted to simulate the tire force in the vehicle model; it was a connecting element in a multi-body system composed of springs and dampers connected in parallel. The main parameters for vehicle modeling are listed in Table $2[32,35]$. 


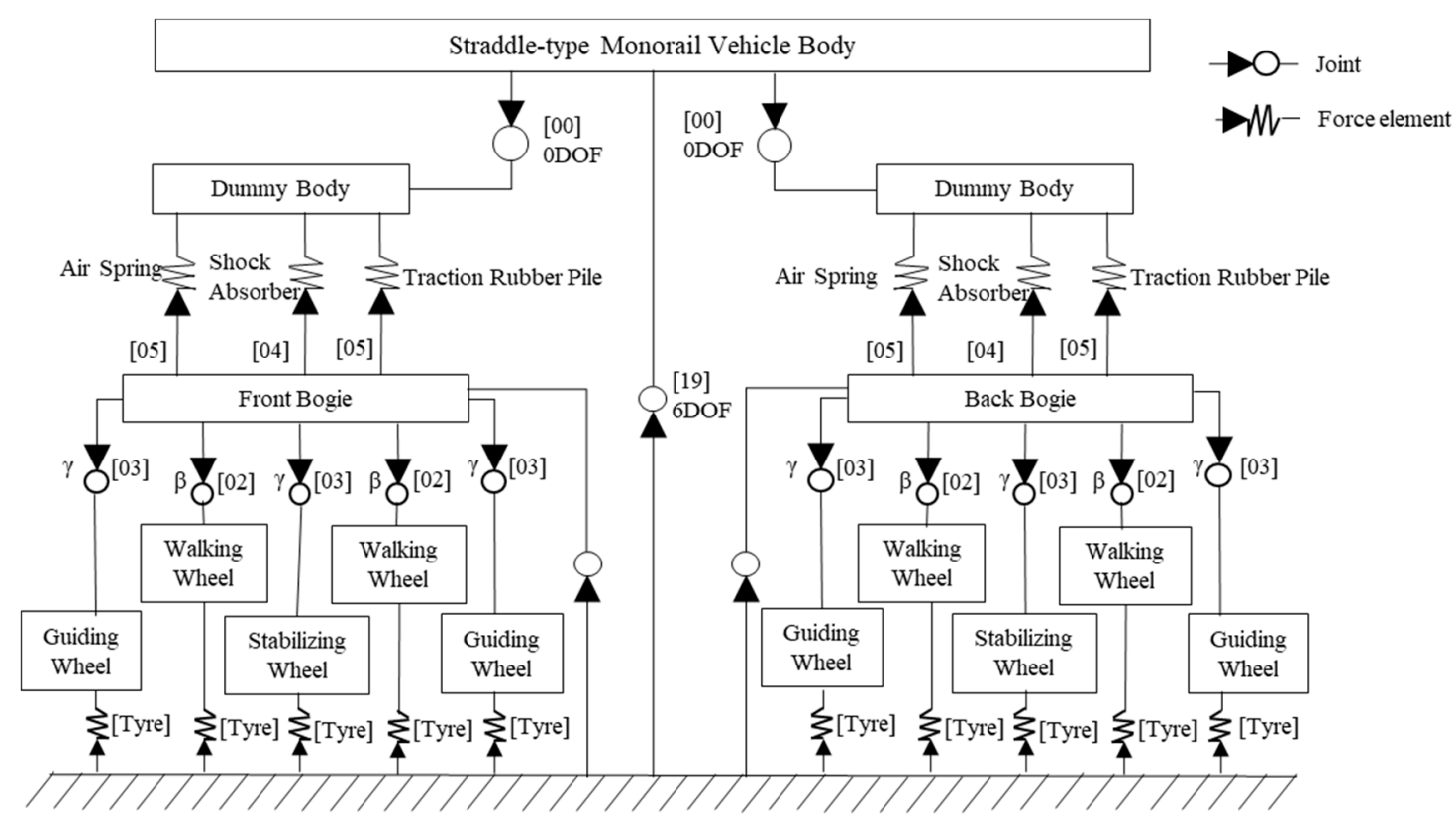

Figure 2. Topology graph of a straddle-type monorail.

Table 2. Main parameters for the monorail vehicle.

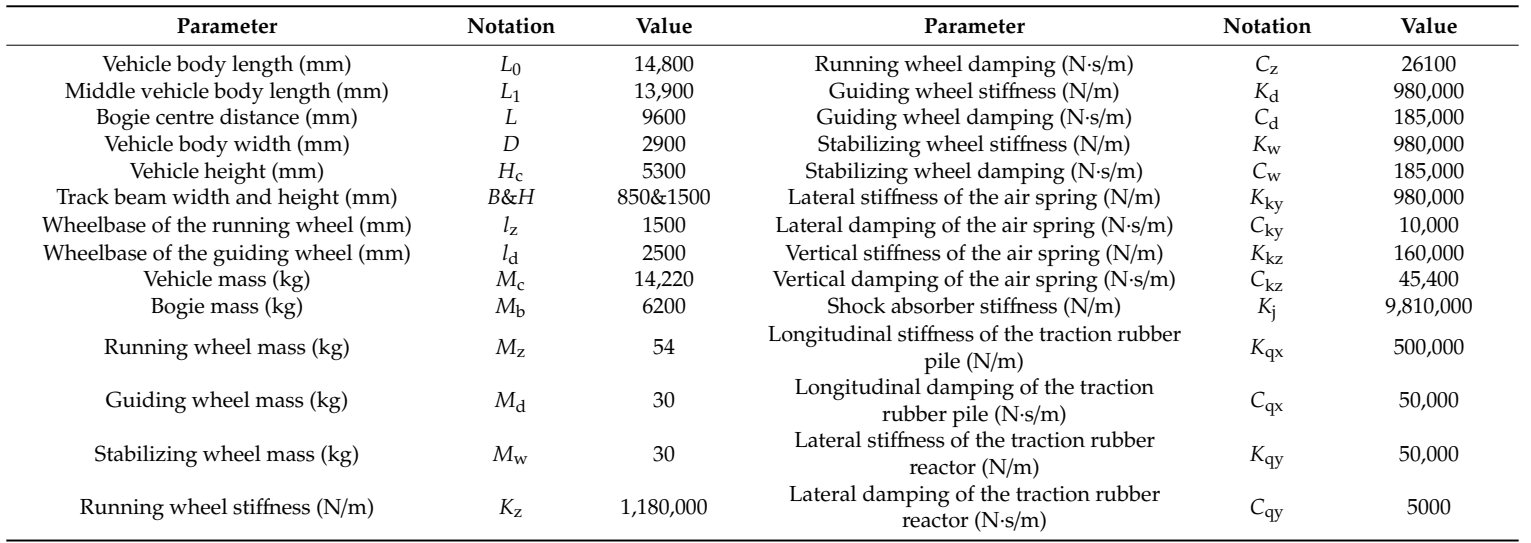

To simplify the dynamic analysis process and improve the efficiency of the solution, the four following basic assumptions were proposed for the vehicle model:

1. The vehicle moved at a constant speed, and the walking wheels always clung to the upper surface of the track beam while driving.

2. The vehicle model was symmetrical about the $X$ and $Y$ axes.

3. The braking and power systems were ignored during modeling; however, their mass and inertia were superimposed on the bogie frames.

4. The body, bogies, and wheels vibrated with minute displacements at their equilibrium positions.

\subsection{Bridge Model}

The superstructure of a monorail bridge consisted of two separate concrete track beams that have low stiffness. Simply supported beam bridges with a span of $22-26 \mathrm{~m}$ were generally used in straddle-type monorail transportation systems. The standard cross-sectional dimensions of the track beam, as shown in Figure 3, were $85 \mathrm{~mm}$ in width and $150 \mathrm{~mm}$ in height. Three middle crossbeams and two end crossbeams were built in each span. The center distance between the two separate track beams was $3.7 \mathrm{~m}$. The piers were made of C 30 concrete with cross-sectional dimensions of $1.7 \mathrm{~m} \times 1.7 \mathrm{~m}$ and 
a coping height of $1.5 \mathrm{~m}$, and the height of the pier was at least $7 \mathrm{~m}$ in this paper, to satisfy the road boundary requirements that the track surface should be approximately $10 \mathrm{~m}$ from the ground.

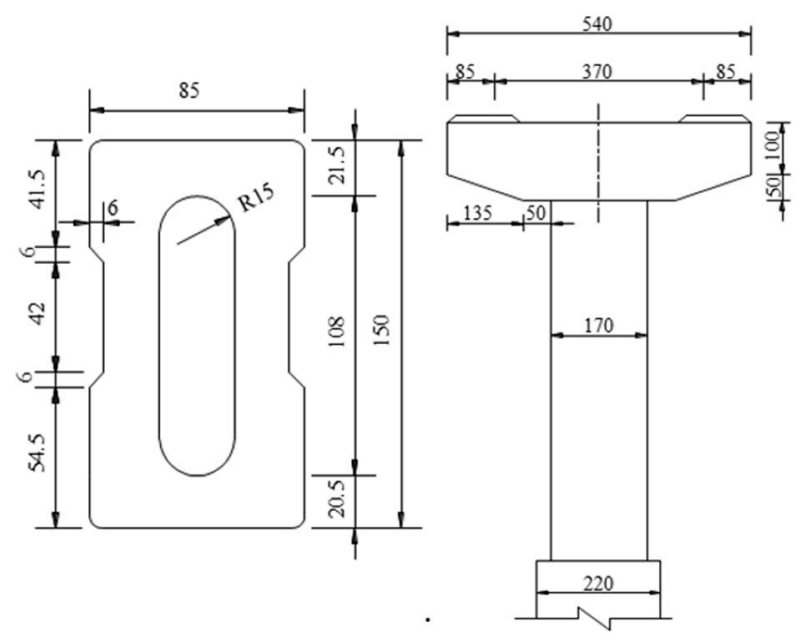

Figure 3. Bridge structure in this paper (mm).

In this study, ANSYS was applied to establish a $3 \mathrm{~m} \times 22 \mathrm{~m}$ double-line simply supported beam bridge model for straddle-type monorail traffic. The dynamic response of a bridge was generally calculated by numerical integration or the mode superposition method. The equation of motion of a bridge model could be written as follows [36]:

$$
\mathbf{M} \ddot{u}+\mathbf{C} \dot{u}+\mathbf{K} u=\mathbf{F}
$$

where $\mathbf{M}, \mathbf{C}$, and $\mathbf{K}$ are the mass matrix, damping matrix, and stiffness matrix, respectively; $\ddot{u}, \dot{u}$, and $u$ are the acceleration, velocity, and displacement of the bridge, respectively; and $\mathbf{F}$ is the external force matrix of the bridge, which is generally the vehicle load matrix or the vehicle-bridge interaction force matrix for the bridge subsystem of a coupled vehicle-bridge system.

Low-order modes are the main focus in vehicle-bridge coupling vibration problems; thus, the lumped mass matrix and the mode superposition method could be used to solve the dynamic response of the bridge. The total displacement of the bridge was the superposition of the components of each mode:

$$
\mathbf{u}=\varphi_{1} Y_{1}+\varphi_{2} Y_{2}+\cdots+\varphi_{N} Y_{N}=\sum_{n=1}^{N} \varphi_{n} Y_{n}=\mathbf{\Phi} \mathbf{Y}
$$

where $\varphi_{n}$ is the mode vector, $\boldsymbol{\Phi}$ is the mode matrix, $\mathbf{Y}$ is the generalized coordinate vector, and $N$ is the number of DOFs of the whole bridge.

To conveniently establish the kinematic relationship between the vehicle and the bridge at the contact points and avoid the conversion and interpolation of degrees of freedom, SOLID73 elements, which had six DOFs at each node, were employed to model the bridge in ANSYS. The FE model of the bridge was divided into 24,544 elements and 38,552 nodes by equidistant FE meshes. Finger-type expansion joints were installed between two adjacent spans to constrain the lateral movement; thus, the transverse DOFs of the corresponding nodes in the track beam were constrained. All six DOFs of the nodes at the bottom of the piers were constrained to simulate the boundary condition. The FE model of a monorail bridge is shown in Figure 4. As the mode superposition method was adopted, the bridge model was limited to linear analysis. 

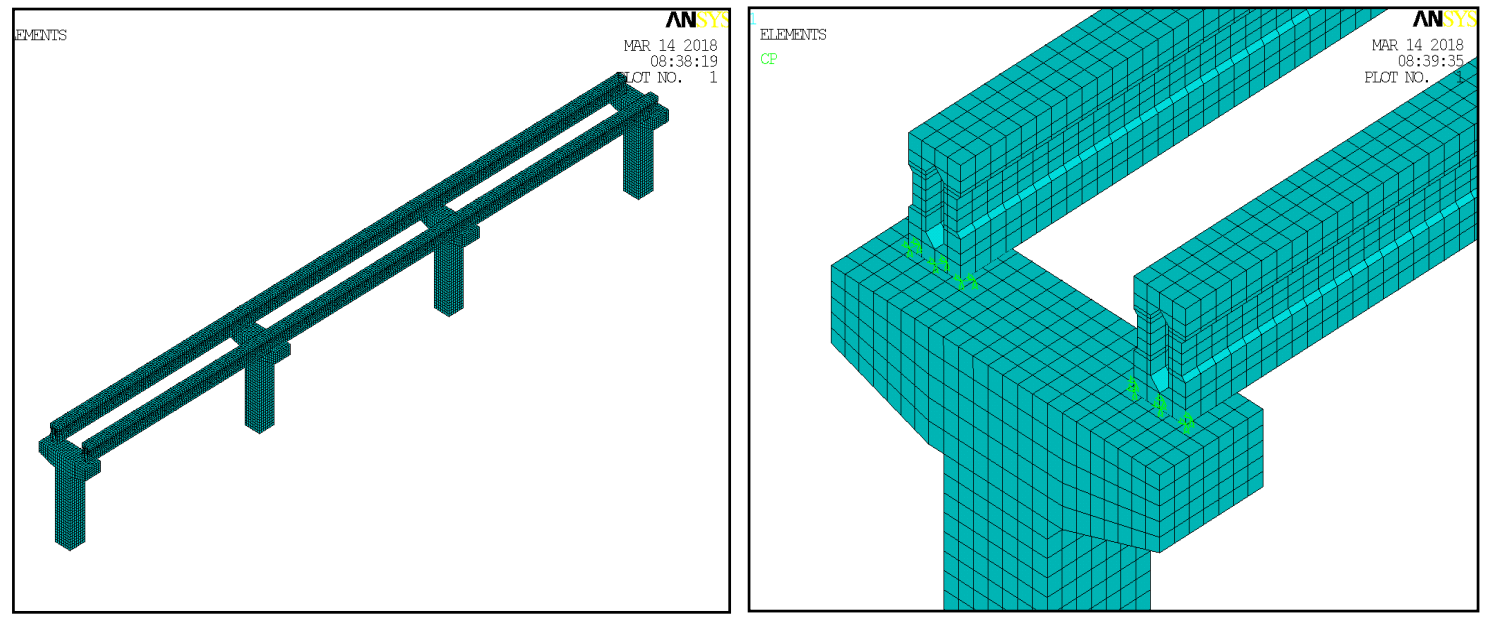

Figure 4. FE model of a monorail bridge.

This study performed modal analysis on the bridge and extracted the results of the first 20 orders. Table 3 illustrates the corresponding frequency and modes, wherein the first-order transverse bending frequency of the bridge was $3.69 \mathrm{~Hz}$, and the first-order vertical bending frequency was $6.42 \mathrm{~Hz}$.

Table 3. Frequencies and vibration modes of the bridge.

\begin{tabular}{ccc}
\hline Order Number & Frequency $\mathbf{( H z )}$ & Vibration Mode \\
\hline 1 & 3.07 & Pier: symmetric lateral bending \\
2 & 3.36 & Pier: asymmetric lateral bending \\
3 & 3.69 & Track beam: first-order symmetric lateral bending \\
4 & 4.21 & Symmetric lateral bending of two track beams-1 \\
5 & 4.36 & Symmetric lateral bending of two track beams-2 \\
6 & 4.50 & Piers bending and beams floating longitudinally \\
7 & 4.55 & Piers bending longitudinally and beam exhibiting \\
& 4.58 & symmetric lateral bending \\
8 & 4.63 & Piers bending longitudinally and beams exhibiting \\
9 & 5.97 & asymmetric lateral bending \\
10 & 6.02 & Piers bending transversely \\
11 & 6.16 & Piers transversely bending and beams exhibiting \\
12 & 6.42 & symmetric lateral bending \\
13 & 6.52 & Piers transversely bending and beams exhibiting \\
14 & 6.63 & asymmetric lateral bending \\
15 & & Piers exhibiting asymmetric transverse bending \\
& & Track beam: first-order symmetric vertical bending \\
& & Track beam: second-order symmetric \\
& & vertical bending \\
\hline
\end{tabular}

\subsection{Track Irregularity}

Track irregularity is the dominant factor in stimulating vehicle vibration and is generally applied as a temporal excitation to the coupled vehicle-bridge system. Straddle-type monorails use pneumatic rubber tires and concrete track beams, and the wheel-rail contact mechanism is distinct from that in traditional railway traffic; obviously, the wheel-rail contact mechanism in straddle-type monorails is similar to the contact between automobile tires and the road surface. The road roughness was obtained from the actual measurement of a large number of road pavements through inspection vehicles, which reflected the wear between the rubber tires and the asphalt or the cement concrete pavement. Thus, it was meaningful to simulate the surface roughness of track beam in a monorail through the road roughness. The vertical irregularity along the longitudinal direction of the route $\mathrm{u}_{\mathrm{z}}$ and the longitudinal irregularity along the lateral direction of the beam surface were simulated in SIMPACK. The national standard road roughness in China was regarded as a stationary Gaussian 
process, and the power spectral density (PSD) function in Equation (3) was introduced to express its statistical characteristics [37]:

$$
G_{q}(n)=G_{q}\left(n_{0}\right)\left(\frac{n}{n_{0}}\right)^{-w}
$$

where $n$ is the spatial frequency, $\mathrm{m}^{-1} ; n_{0}$ is the reference spatial frequency, whose value in this study was $0.1 \mathrm{~m}^{-1} ; G_{q}\left(n_{0}\right)$ is the coefficient of road roughness, $\mathrm{m}^{2} / \mathrm{m}^{-1}$, whose value is shown in Table 4 ; and $\mathrm{w}$ is the frequency index, whose value in this study was 2 .

Table 4. The coefficient of road roughness.

\begin{tabular}{|c|c|c|c|}
\hline The Level & $\begin{array}{l}\text { The Average Value of } \mathrm{G}_{\mathrm{q}}\left(\mathrm{n}_{0}\right) \\
\left(\mathbf{1 0}^{-6} \mathrm{~m}^{2} / \mathrm{m}^{-1}\right)\end{array}$ & The Level & $\begin{array}{l}\text { The Average Value of } G_{q}\left(n_{0}\right) \\
\qquad\left(10^{-6} \mathrm{~m}^{2} / \mathrm{m}^{-1}\right)\end{array}$ \\
\hline A & 16 & E & 4096 \\
\hline B & 64 & F & 16,384 \\
\hline C & 256 & G & 65,536 \\
\hline D & 1024 & $\mathrm{H}$ & 262,144 \\
\hline
\end{tabular}

The surface roughness of the track beam based on the A- and B-level national standard road roughness are simulated with Equation (3) through the trigonometric series methods, and the samples are illustrated in Figure 5.

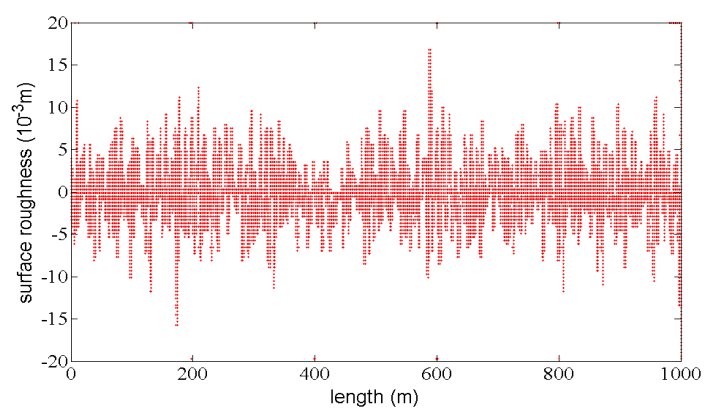

(a)

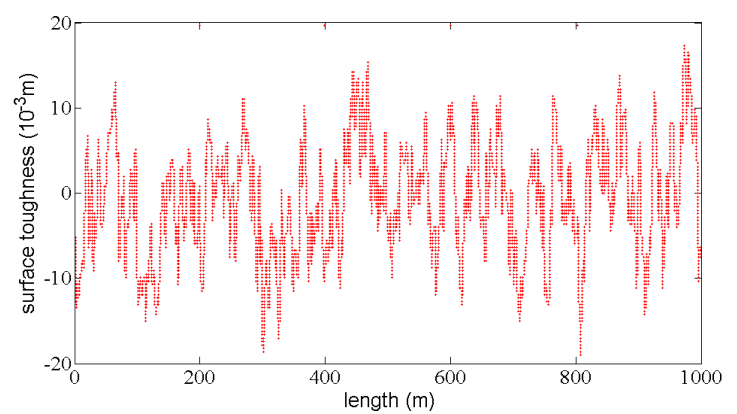

(b)

Figure 5. The surface roughness based on the national standard road roughness: (a) A-level and (b) B-level.

As a type of rail transit, the straddle-type monorail was restricted by railway regulations in several aspects. Naturally, the requirements for track irregularity were stricter than those for road roughness. Although it was difficult and unnecessary for the track beam roughness of straddle-type monorail to meet the requirements of rails due to the influence of factors like materials, manufacturing processes, operating conditions, and operating speeds, the railway irregularity still had reference significance to the straddle-type monorail. The surface irregularity of the track beam in a straddle-type monorail system was actually between the road roughness and the railway track irregularity. A representative irregularity of the railway was American six-level track irregularity. Hence, it was meaningful to simulate the surface irregularity through American six-level track irregularity. The PSD functions of American six-level track irregularity are shown as Equation (4) [38]:

$$
\begin{aligned}
& S_{V}(\Omega)=\frac{k \mathrm{~A}_{V} \Omega_{c}^{2}}{\Omega^{2}\left(\Omega^{2}+\Omega_{c}^{2}\right)} \\
& S_{\alpha}(\Omega)=\frac{k \mathrm{~A}_{\alpha} \Omega_{c}^{2}}{\Omega^{2}\left(\Omega^{2}+\Omega_{c}^{2}\right)} \\
& S_{c}(\Omega)=S_{g}(\Omega)=\frac{4 k \mathrm{~A}_{V} \Omega_{c}^{2}}{\left(\Omega^{2}+\Omega_{c}^{2}\right)\left(\Omega^{2}+\Omega_{s}^{2}\right)}
\end{aligned}
$$

where $\mathrm{S}_{\mathrm{V}}(\Omega), \mathrm{S}_{\alpha}(\Omega), \mathrm{S}_{\mathrm{c}}(\Omega)$, and $\mathrm{S}_{\mathrm{g}}(\Omega)$ are the PSD of the track longitudinal irregularity, track alignment irregularity, horizontal irregularity, and gauge irregularity, respectively; $\Omega$ is the angular spatial frequency, $\mathrm{rad} / \mathrm{m} ; \mathrm{k}$ is the safety factor, whose value was $0.25 ; \Omega_{\mathrm{c}}$ and $\Omega_{\mathrm{s}}$ are the cutoff frequencies, 
$\mathrm{rad} / \mathrm{m}$, whose values were 0.8245 and 0.4380 respectively; and $A_{V}$ and $A_{\alpha}$ are the roughness constants, $\mathrm{cm}^{2} / \mathrm{rad} / \mathrm{m}$, whose values were 0.0339 and 0.0339 , respectively.

American six-level track irregularity was simulated by the trigonometric series method and converted into the surface roughness parameters of the track beam, through Equation (5) [39]. The vertical and longitudinal surface roughness of the track beam are shown in Figure 6:

$$
\left[\begin{array}{l}
u_{y} \\
u_{z} \\
u_{\varphi} \\
d_{y}
\end{array}\right]=\left[\begin{array}{cccc}
\frac{1}{2} & \frac{1}{2} & 0 & 0 \\
0 & 0 & \frac{1}{2} & \frac{1}{2} \\
0 & 0 & -\frac{1}{e_{0}} & \frac{1}{e_{0}} \\
1 & -1 & 0 & 0
\end{array}\right]\left[\begin{array}{l}
y_{1} \\
y_{2} \\
z_{1} \\
z_{2}
\end{array}\right]
$$

where $\mathrm{u}_{\mathrm{y}}$ is the alignment irregularity of American six-level track irregularity; $\mathrm{u}_{\mathrm{z}}$ is the longitudinal irregularity of American six-level track irregularity; $\mathrm{u}_{\varphi}$ is the horizontal irregularity of American six-level track irregularity; $d_{y}$ is the gauge irregularity of American six-level track irregularity; $z_{1}$ and $\mathrm{z}_{2}$ are the track beam roughness values of the left and the right walking wheels in the vertical direction, respectively; $\mathrm{y}_{1}$ and $\mathrm{y}_{2}$ are the track beam roughness values of the left and the right walking wheels in the longitudinal direction, respectively; and $\mathrm{e}_{0}$ is a constant, whose value is 1 .

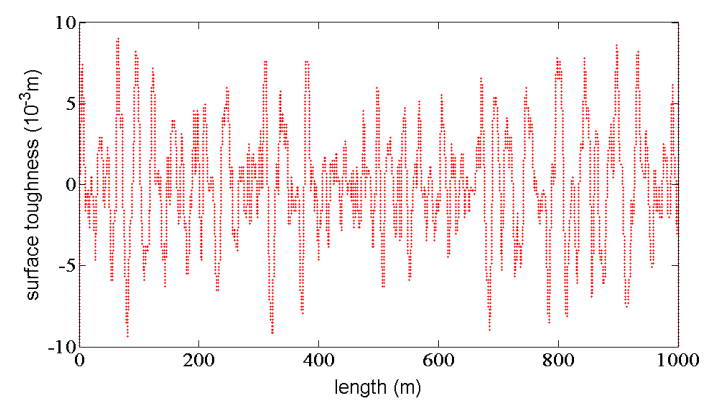

(a)

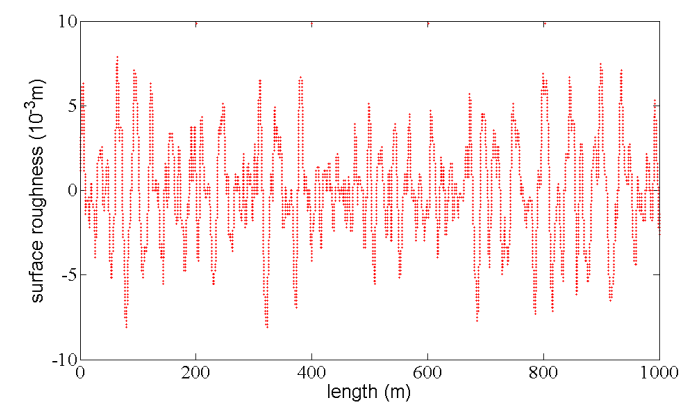

(b)

Figure 6. The surface roughness based on American six-level track irregularity-(a) vertical and (b) longitudinal.

Japanese researchers have fitted the PSD function of surface irregularity for steel track beams in a monorail, based on measured data, as shown in Equation (6) [40]. Although the surface roughness of steel track beams is lower than that of concrete track beams, the surface roughness of the steel track beams is meaningful for the study of the dynamic response, as measured in practice. The surface roughness of a track beam based on Japanese steel tracks is shown in Figure 7.

$$
S_{z 0}(\Omega)=\frac{\alpha}{\Omega^{n}+\beta^{n}}
$$

where $\Omega$ is the angular spatial frequency, and $\alpha, \beta$, and $n$ are the tire-related constants, which were $0.0005,0.35$, and 3.00 for the walking wheels, $0.0006,0.50$, and 2.80 for the guiding wheels, and 0.0006 , 0.50 , and 2.60 for the stabilizing wheels, respectively. 


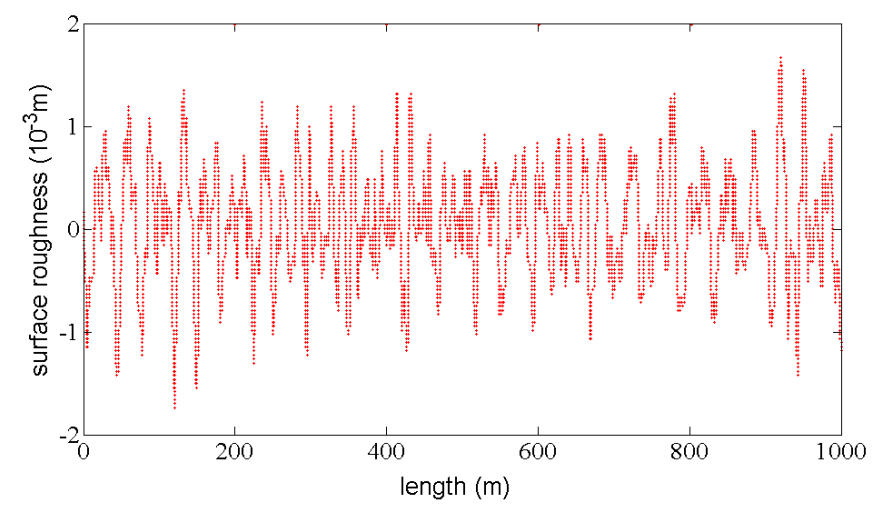

Figure 7. The surface roughness based on Japanese steel track irregularity.

The range of surface roughness based on the national standard road roughness was the largest, of which the A-level was -10 to $10 \mathrm{~mm}$ and the B-level was -20 to $20 \mathrm{~mm}$. The range of the surface roughness based on American six-level track irregularity was -8 to $8 \mathrm{~mm}$, and the surface roughness based on the Japanese steel track irregularity was -2 to $2 \mathrm{~mm}$. The surface roughness of the concrete track beams in a straddle-type monorail, which lacked the measured data and the fitted PSD, was within the above roughness ranges. Therefore, three types of surface roughness were simulated to study the influence of irregularity on the vehicle-bridge coupled system in this study.

\subsection{Coupled System of a Straddle-Type Monorail and a Bridge}

Co-simulations with the FE software are supported in SIMPACK. The size of the FE model must be reduced before performing the co-simulation, as the number of DOFs in the FE model could reach $10^{6}$, while the multibody model had approximately 500 DOFs. The Guyan reduction method was applied to the substructure analysis in ANSYS, and the whole bridge model was reduced into a super-element that included the mass, stiffness, and damping information. All DOFs of the wheel-track contact points in the bridge FE model were selected as the main DOFs, according to the requirements of the co-simulation. The motion equation of the reduced bridge model [41] is shown in Equation (7):

$$
\left[K_{z z}\right]^{*}\left\{U_{z}\right\}=\left\{F_{z}\right\}^{*}
$$

where $\left[K_{z z}\right]^{*}$ is the stiffness matrix of the super-element, $\left\{U_{z}\right\}$ is the main DOF vector, and $\left\{F_{z}\right\}^{*}$ is the reduction power vector.

The modal analysis on the bridge substructure was performed, and the mass, stiffness, geometric and modal information of the bridge were stored in the corresponding files. Bridge information was read by the interface program FEMBS, and the bridge super-element was introduced into SIMPACK as an elastic track. The contact points were then defined by the interface program FEMBS. There was a contact relationship between the guide wheels, stabilizing wheels, and the side surface of the track beam. A moving point was established on these tires, and another moving point and a contact line were established on the track beam. The two points always moved along the contact line, and a force element was established between the moving points to simulate the contact force. The walking wheels were always in contact with the upper surface of the track beam, and the contact relationship was divided into uniform contact points by the meshing of the bridge finite element model. At the walking wheel-track contact points, the vehicle subsystem and the bridge subsystem had interaction forces and consistent displacements, and the coupled monorail-bridge system was established through data transmission of those points. The equations of motion of the vehicles and bridges were independent. Iterative calculation was performed in each time step, until the calculation error of the interaction force or the displacement of the two motion equations met the accuracy, and then the next integration step was executed. The process of coupling is depicted in Figure 8. The model of the straddle-type monorail-bridge coupled system is shown in Figure 9. 


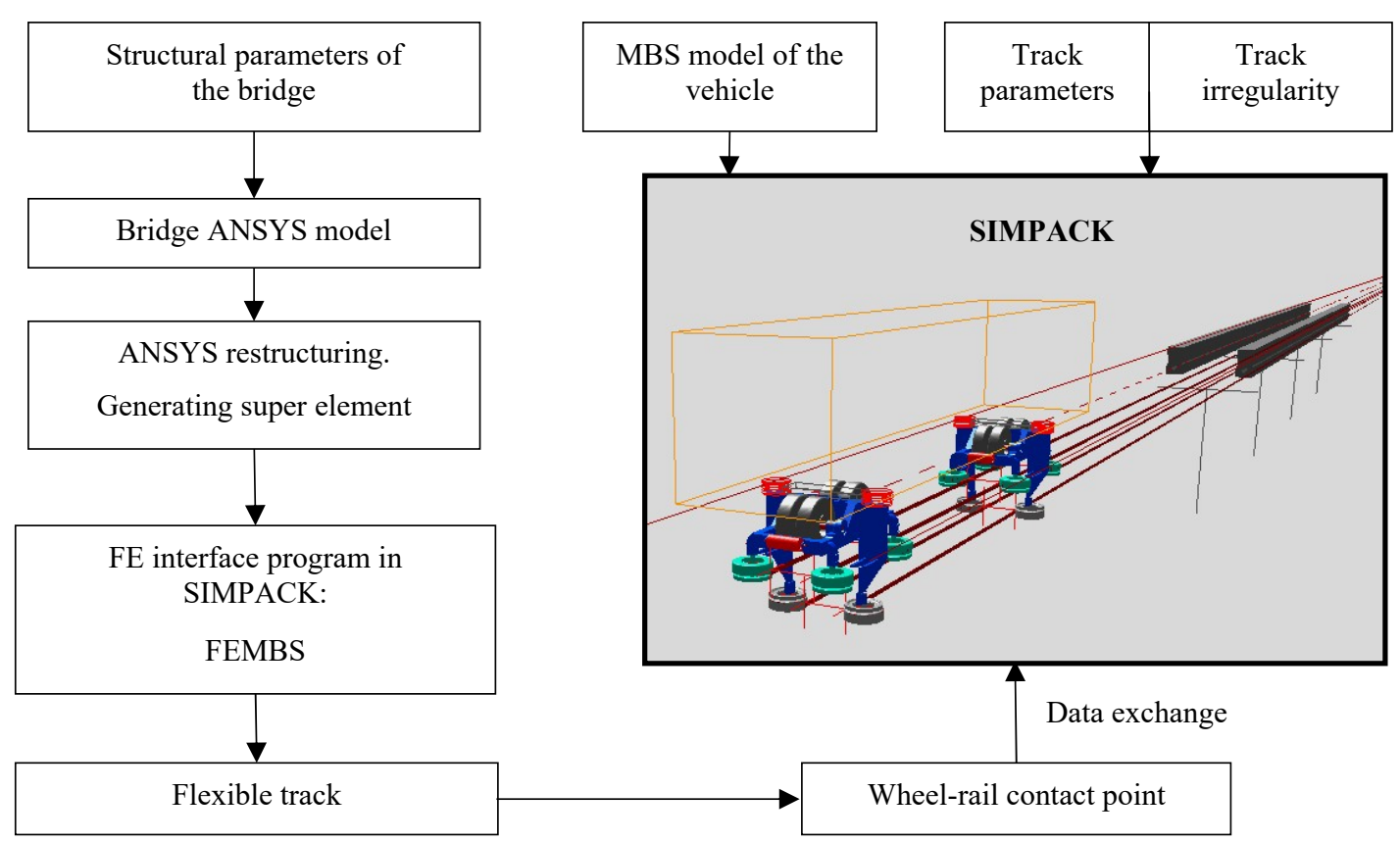

Figure 8. Coupling process of the vehicle-bridge system.

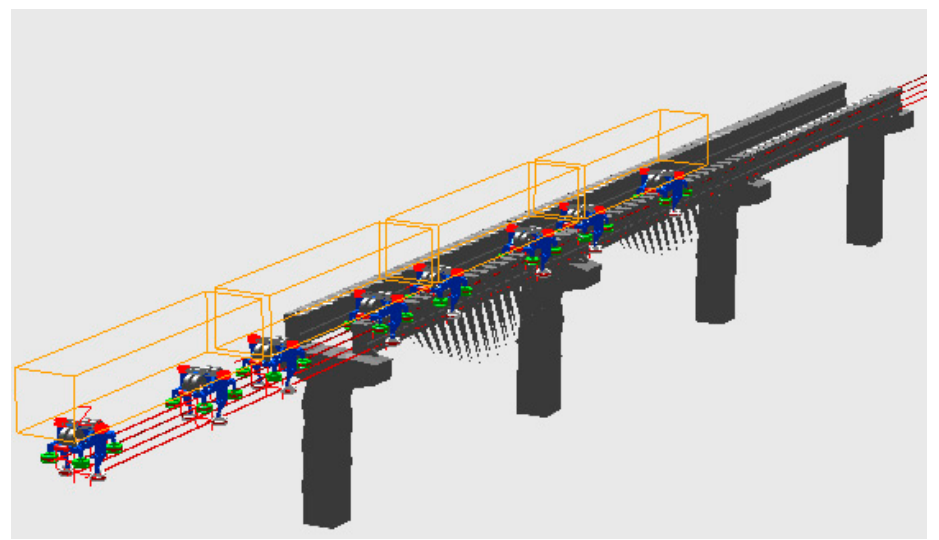

Figure 9. Model of the vehicle-bridge coupled system.

\section{Dynamic Performance of a Straddle-Type Monorail}

The dynamic response of a bridge is of great importance to bridge safety and vehicle operations, whereas riding comfort can reflect the vehicle operation and passenger experience. Evaluation criteria for the dynamic response of a straddle-type monorail bridge and the riding comfort of monorail traffic were proposed in this study. The influence of the vehicle speed, bridge pier height, track irregularity, and vehicle load on the bridge response and the riding comfort were studied.

\subsection{Evaluation Indices}

In the vehicle-bridge coupling dynamic analysis, the natural frequency, acceleration, deflection, and bending angle were the major parameters for evaluating the dynamic response of a bridge. These indicators of railway bridges were well-evaluated and formed a specific evaluation criterion that could be applied to straddle-type monorail bridges as a reference.

Riding comfort consists of running safety and running stability. Running safety indicated that the train did not derail or overturn, which is usually evaluated by the derailment coefficient, the rate of wheel load reduction, the lateral wheelset force, the overturning coefficient, and other indicators. There were stability wheels and guiding wheels on both sides of the straddle-type monorail bogie 
to hold the track beam, so train derailment and overturning were not applicable. Running stability reflected the vibration performance of a vehicle and the riding comfort of passengers, which is usually evaluated by the maximum acceleration of the vehicle vibration and the Sperling comfort index.

\subsubsection{Deflection of the Bridge}

To maintain the actual stress state of the bridge within the design range, the bridge deformations in transverse and vertical direction should be controlled. National standard TB 10002-2017 stipulates that the transverse deflection of a railway bridge beam should not exceed L/4000 [42], whereas national standard GB 50458-2008 stipulates that the vertical deflection of a monorail track beam should not exceed L/800 [43]. As L was $22 \mathrm{~m}$ in this study, the deflection limits were $5.5 \mathrm{~mm}$ in the transverse direction and $27.5 \mathrm{~mm}$ in the vertical direction.

\subsubsection{Vibration Acceleration of the Bridge}

It was essential to control the vibration acceleration of the bridge in case of structural failure of the track under strenuous bridge dynamic responses. National standard TB 10002-2017 stipulates that the maximum limit value for the bridge vertical vibration acceleration of a railway with a design speed of $200 \mathrm{~km} / \mathrm{h}$ is $3.5 \mathrm{~m} / \mathrm{s}^{2}$ for ballasted bridge decks, and $5.0 \mathrm{~m} / \mathrm{s}^{2}$ for unballasted bridge decks. The test results from the Japanese railways showed that train derailment was likely to occur when the lateral vibration acceleration of the bridge reached $0.1-0.2 \mathrm{~g}$.

Considering the above evaluation criteria, in this study, the lateral vibration acceleration limit of the bridge was set to $0.1 \mathrm{~g}$ (i.e., $1.0 \mathrm{~m} / \mathrm{s}^{2}$ ), and the vertical vibration acceleration limit of the bridge was set to $3.5 \mathrm{~m} / \mathrm{s}^{2}$.

\subsubsection{Angle of the Bridge}

To avoid excessive lateral displacement caused by the torsion of the beam, the midspan torsion angle in the beam needed to be limited, and the limit value was $5.0 \%$ rad. Under the vertical load of a train, the vertical bending angles increased at the beam ends. The bending angle of a beam end was an index reflecting the stability of the track structure, and an excessive value would affect the safety of train operations. This study took the corresponding limit as $1.5 \%$ rad.

\subsubsection{Rate of Wheel Load Reduction}

The rate of wheel load reduction was defined as the ratio between the load reduction of one wheel and the average load of the wheelset, as shown in Equation (8), which was used to evaluate the running safety of vehicles. In straddle-type monorail systems, the rate of wheel load reduction was adopted to limit side slip, which was caused by excessive load reduction on one side of a wheelset:

$$
\frac{\Delta P}{P}=\frac{P_{1}-P_{2}}{P_{1}+P_{2}}
$$

where $P_{1}$ and $P_{2}$ are the vertical forces of the walking wheels on the same wheelset.

According to the Chinese national standard 'Dynamic performance evaluation and test appraisal regulations for railway vehicles' (GB 5599-85) [44], $\Delta P / p \leq 0.6$ was the eligibility criterion for the running safety of vehicles.

\subsubsection{Vibration Acceleration of the Train Body}

The vertical and lateral accelerations of the vehicle body directly affected the riding comfort of the passengers. National standard GB 5599-85 stipulates the maximum values of the vibration acceleration for passenger trains-the vertical vibration acceleration limit was $2.0 \mathrm{~m} / \mathrm{s}^{2}(0.20 \mathrm{~g})$, and the lateral vibration acceleration limit was $1.5 \mathrm{~m} / \mathrm{s}^{2}(0.15 \mathrm{~g})$. 
The standard 'Evaluation Method and Standard for Railway Locomotive Dynamic Test' (TB/T 2360-93), which was formulated by the Ministry of Railways, stipulates the evaluation rules for train body acceleration when a train is crossing a bridge [45]; shown in Table 5. Considering the above two standards, in this study, the vertical acceleration limit and transverse acceleration limit of the train body were $2.00 \mathrm{~m} / \mathrm{s}^{2}$ and $1.47 \mathrm{~m} / \mathrm{s}^{2}$, respectively.

Table 5. Evaluation standards for the vibration acceleration of a train body.

\begin{tabular}{cccc}
\hline Class & Excellent & Well & Pass \\
\hline Vertical acceleration $\left(\mathrm{m} / \mathrm{s}^{2}\right)$ & 2.45 & 2.95 & 3.63 \\
\hline Transverse acceleration $\left(\mathrm{m} / \mathrm{s}^{2}\right)$ & 1.47 & 1.98 & 2.45 \\
\hline
\end{tabular}

\subsubsection{Sperling Comfort Index}

Passenger riding comfort was affected by various factors of the train and environment, among which the vehicle vibration acceleration was the major factor. The Sperling index, which is based on vehicle acceleration, is widely used in riding comfort evaluations. The vibration acceleration of a vehicle body usually includes multiple frequency components, and to calculate the Sperling index, the vehicle body acceleration time history must be decomposed into $n$ groups, according to the frequency. First, the values of $W_{i}$ were obtained under each frequency group, which were then converted to the Sperling index $W z$ over the entire time history, according to Equation (9):

$$
W_{z}=0.896 \sqrt[10]{\sum_{i=1}^{n} \frac{A_{i}^{3}}{f_{i}} F\left(f_{i}\right)}=\sqrt[10]{\sum_{i=1}^{n} W_{i}^{10}}
$$

where $\mathrm{A}_{i}$ is the amplitude of vibration acceleration in the $\mathrm{i}$-th acceleration group at the mass center of the vehicle body, $\mathrm{m} / \mathrm{s}^{2} ; \mathrm{f}_{i}$ is the frequency of vehicle vibration, $\mathrm{Hz}$; and $\mathrm{F}\left(\mathrm{f}_{i}\right)$ is the frequency correction coefficient, which is related to the frequency range and vibration direction of the vehicle body, whose calculation method is shown in Table 6. The evaluation standards of the Sperling index are shown in Table 7. For a straddle-type monorail system, the Sperling index should achieve an excellent level or a favorable level.

Table 6. The value of the frequency correction coefficient $F(f)$.

\begin{tabular}{cccc}
\hline The Frequency of Vertical Vibration & F(f) & The Frequency of Horizontal Vibration & F(f) \\
\hline$f<0.5 \mathrm{~Hz}$ & 0 & $f<0.5 \mathrm{~Hz}$ & 0 \\
$0.5 \mathrm{~Hz}<f<5.9 \mathrm{~Hz}$ & $0.325 f^{2}$ & $0.5 \mathrm{~Hz}<f<5.4 \mathrm{~Hz}$ & $0.8 f^{2}$ \\
$5.9 \mathrm{~Hz}<f \leq 20 \mathrm{~Hz}$ & $400 / f^{2}$ & $5.4 \mathrm{~Hz}<f \leq 26 \mathrm{~Hz}$ & $650 / f^{2}$ \\
$f>20 \mathrm{~Hz}$ & 1 & $f>26 \mathrm{~Hz}$ & 1 \\
\hline
\end{tabular}

Table 7. Evaluation standards for the vibration acceleration of a train body.

\begin{tabular}{ccccc}
\hline & \multirow{2}{*}{ Class } & \multicolumn{3}{c}{ Index $\boldsymbol{W}_{\mathbf{z}}$} \\
\cline { 3 - 5 } & & Locomotive & Passenger Train & Freight Train \\
\hline I & Excellent & $<2.75$ & $<2.5$ & $<3.5$ \\
II & Favorable & $2.75 \sim 3.10$ & $2.5 \sim 2.75$ & $3.5 \sim 4.0$ \\
III & Pass & $3.10 \sim 3.45$ & $2.75 \sim 3.0$ & $4.0 \sim 4.25$ \\
\hline
\end{tabular}

\subsection{Effect of the Train Speed}

When studying the influence of monorail speed on the bridge response, the speed range was considered to be $20-80 \mathrm{~km} / \mathrm{h}$. The monorail train consisted of four carriages, and the American six-level track irregularity and rated load were adopted in this case. To reduce the influence of the interaction between the carriages on the dynamic response, the first carriage \#1 and the second carriage \#2 were comprehensively considered, when calculating the vehicle acceleration, Sperling index, and wheel 
load reduction rate. The variation curves of the bridge response and vehicle responses under different speeds are shown in Figure 10.

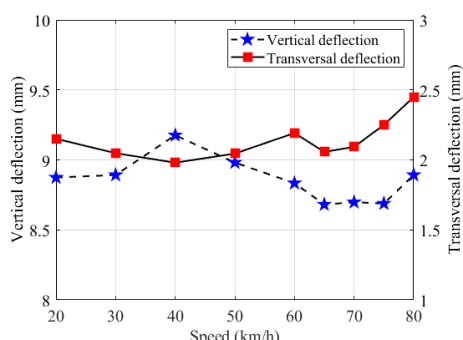

(a)

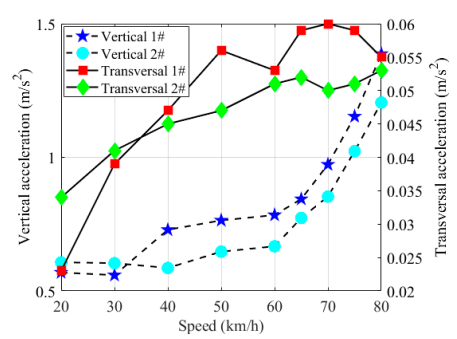

(d)

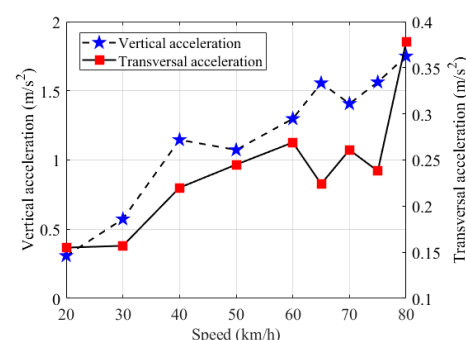

(b)

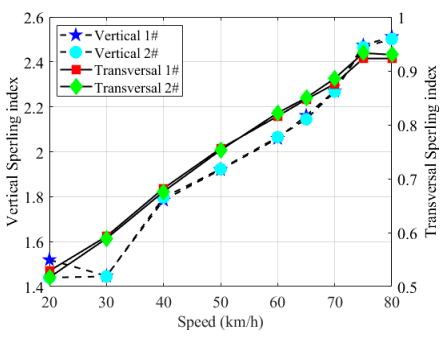

(e)

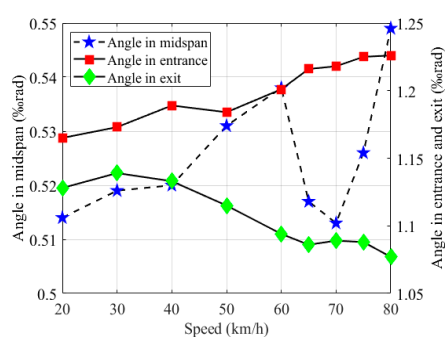

(c)

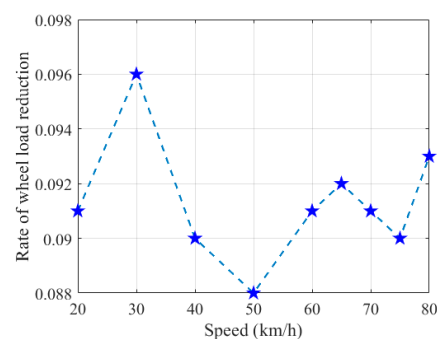

(f)

Figure 10. Responses of the bridge and the train under different speeds: (a) bridge deflection, (b) bridge acceleration, (c) bridge angle, (d) train acceleration, (e) Sperling index, and (f) rate of wheel load reduction.

Figure 10a-c shows that the vertical deflection, lateral displacement, and torsion angle of the bridge midspan and the bending angles of the beam ends were less affected by the change in vehicle speed, whereas the vertical and lateral accelerations of the bridge were positively correlated with vehicle speed. Figure 10d-f shows that the maximum values of the vertical and transverse acceleration responses of the vehicle body were $1.387 \mathrm{~m} / \mathrm{s}^{2}$ and $0.060 \mathrm{~m} / \mathrm{s}^{2}$, respectively, which were both less than the corresponding limit values of $2.00 \mathrm{~m} / \mathrm{s}^{2}$ and $1.47 \mathrm{~m} / \mathrm{s}^{2}$. The acceleration of the mass center and the Sperling index of the vehicle body all increased with increasing speed, and the vertical response changed more dramatically; hence, the faster the vehicle speed, the worse the vehicle stability. The maximum value for the rate of wheel load reduction was 0.096 , which was less than the limit of 0.6 , indicating that the safety of vehicle operation could be fully guaranteed. The wheel weight reduction rate was less affected by the change in speed. The vertical Sperling index reached 2.512 and the vertical comfort level of the train was 'good' when the monorail speed was $80 \mathrm{~km} / \mathrm{h}$; in other speed cases, the vertical Sperling index was less than 2.5, and the vertical comfort reached 'excellent' status.

\subsection{Effect of the Pier Height}

This study considered pier heights of $7 \mathrm{~m}, 8 \mathrm{~m}, 9 \mathrm{~m}, 10 \mathrm{~m}, 11 \mathrm{~m}, 12 \mathrm{~m}$, and $13 \mathrm{~m}$, and the cross-sectional dimensions of the 11-13 m-high piers were appropriately increased. A speed of $65 \mathrm{~km} / \mathrm{h}$, the American six-level track irregularity and a rated load were adopted in this case. The effect of the pier height on the coupled vehicle-bridge system was mainly realized by changing the linear stiffness of piers, as shown in Table 8. The variation curves of the bridge response and vehicle responses are shown in Figure 11. 
Table 8. Linear stiffness of a bridge pier.

\begin{tabular}{|c|c|c|c|c|c|c|c|c|}
\hline $\begin{array}{l}\text { Height } \\
\text { (m) }\end{array}$ & $\begin{array}{l}\text { Width } \\
\text { (m) }\end{array}$ & $\begin{array}{l}\text { Stiffness } \\
(\mathrm{kN} / \mathrm{cm})\end{array}$ & $\begin{array}{l}\text { Height } \\
\text { (m) }\end{array}$ & $\begin{array}{l}\text { Width } \\
\text { (m) }\end{array}$ & $\begin{array}{l}\text { Stiffness } \\
(\mathrm{kN} / \mathrm{cm})\end{array}$ & $\begin{array}{l}\text { Height } \\
\text { (m) }\end{array}$ & $\begin{array}{l}\text { Width } \\
\text { (m) }\end{array}$ & $\begin{array}{l}\text { Stiffness } \\
(\mathrm{kN} / \mathrm{cm})\end{array}$ \\
\hline 7 & 1.70 & 1352 & 11 & 1.80 & 508 & 12 & 1.85 & 446 \\
\hline 8 & 1.70 & 954 & 10 & 1.70 & 524 & 13 & 1.90 & 400 \\
\hline 9 & 1.70 & 697 & & & & & & \\
\hline
\end{tabular}

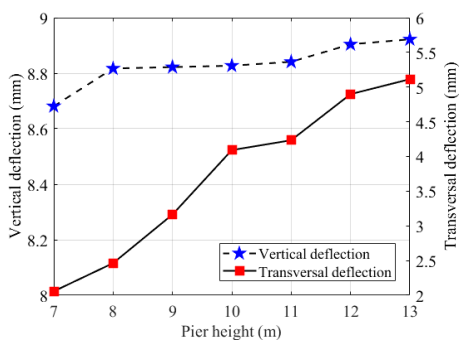

(a)

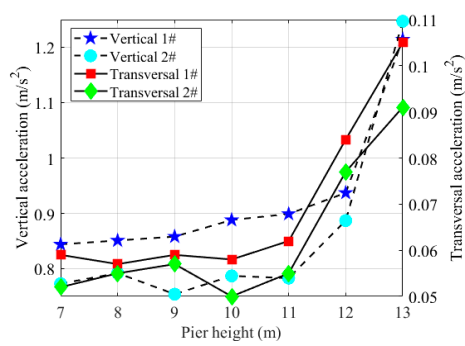

(d)

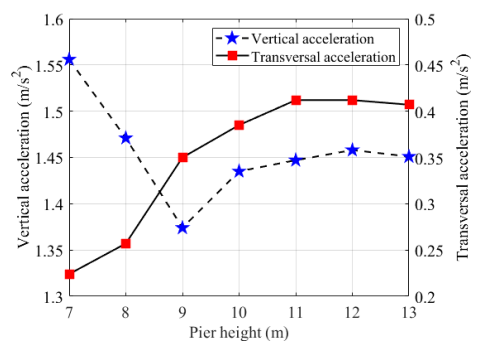

(b)

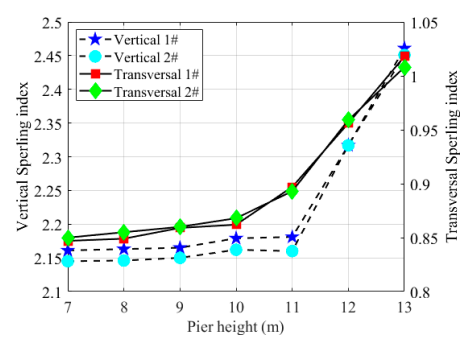

(e)

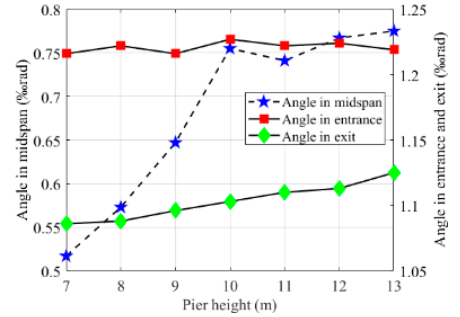

(c)

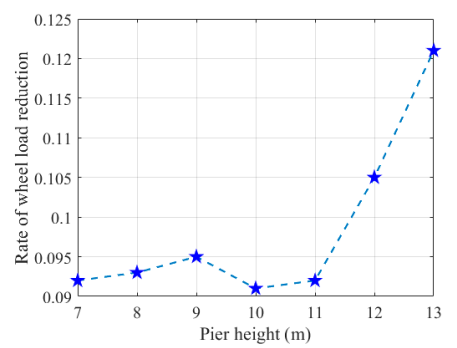

(f)

Figure 11. Responses of the bridge and the train at different pier heights-(a) bridge deflection, (b) bridge acceleration, (c) bridge angle, (d) train acceleration, (e) Sperling index, and (f) rate of wheel load reduction.

Figure $11 \mathrm{a}-\mathrm{c}$ show that-except for the vertical acceleration in the midspan of the bridge-all bridge responses decreased as the linear stiffness of the pier increased, and the transverse dynamic responses of the bridge were more sensitive to the linear stiffness of the pier than the vertical dynamic responses. When piers had low linear stiffness, the bridge exhibited greater flexibility, and the dynamic responses were more greatly affected by the linear stiffness of the piers. When the linear stiffness of the piers exceeded $550 \mathrm{kN} / \mathrm{cm}$, all dynamic responses of the bridge were in good condition, and the travelling comfort of the straddle-type monorail could be guaranteed.

Figure $11 \mathrm{~d}-\mathrm{f}$ illustrates that the maximum values of the vehicle responses were all less than their limit values, and the comfort evaluation results were all in 'excellent' state. However, the vertical Sperling index reached 2.461, which was close to the limit value of 2.5 for the 'excellent' state. As the linear stiffness of the pier increased, all accelerations at the mass center, the Sperling index of the vehicle, and the rate of wheel load reduction decreased, and the riding comfort increased, among which the lateral responses of the monorail vehicle were greatly affected by the linear stiffness of the pier. When the linear stiffness exceeded $550 \mathrm{kN} / \mathrm{cm}$, the riding comfort of the straddle-type monorail was guaranteed. When the linear stiffness was less than $550 \mathrm{kN} / \mathrm{cm}$, the bridge exhibited greater flexibility, and the responses of the vehicle were very sensitive to changes in the linear stiffness of the pier and increased sharply, as this stiffness increased; moreover, the riding comfort and riding stability of the vehicles became worse in response to these changes. 


\subsection{Effect of the Track Irregularity}

To examine this effect, five cases were considered-no track irregularity, Japanese spectrum track irregularity, American six-level track irregularity, and the national standard road roughness levels A and $\mathrm{B}$, for which the roughness values increased successively. The monorail traveled at a speed of 65 $\mathrm{km} / \mathrm{h}$ under standard loading, whereas the height of the pier was $7 \mathrm{~m}$.

A comparison of the bridge and vehicle dynamic responses under different track irregularity excitations are shown in Figure 12. The results showed that the maximum value of vertical deflection and lateral displacement in the midspan of the bridge were $9.788 \mathrm{~mm}$ and $2.294 \mathrm{~mm}$, which were within the limits. The maximum vertical acceleration of the bridge was $4.722 \mathrm{~m} / \mathrm{s}^{2}$, which exceeded the limit of $3.50 \mathrm{~m} / \mathrm{s}^{2}$, thereby posing a severe threat to bridge safety. The maximum vertical acceleration of the vehicle body was $2.451 \mathrm{~m} / \mathrm{s}^{2}$, which exceeded the limit of $2.00 \mathrm{~m} / \mathrm{s}^{2}$. The maximum transverse acceleration of the vehicle body was $0.082 \mathrm{~m} / \mathrm{s}^{2}$, which was far less than the limit of $1.47 \mathrm{~m} / \mathrm{s}^{2}$. The maximum vertical Sperling index was 2.906 , and the vertical comfort was very poor, which was in the 'qualified' state, whereas the maximum transverse Sperling index was 1.177, and the transverse comfort reached the 'excellent' state.

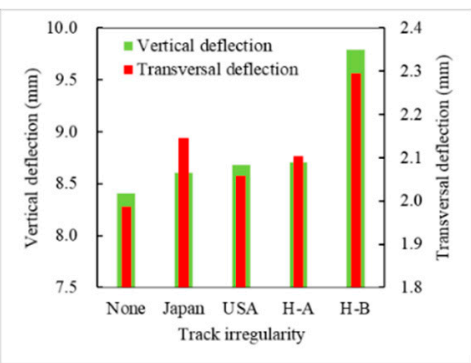

(a)

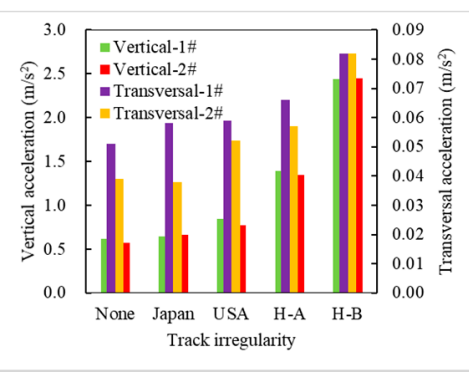

(d)

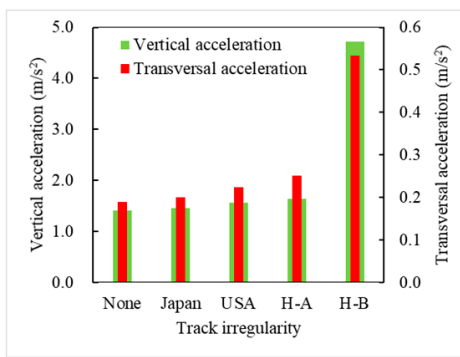

(b)

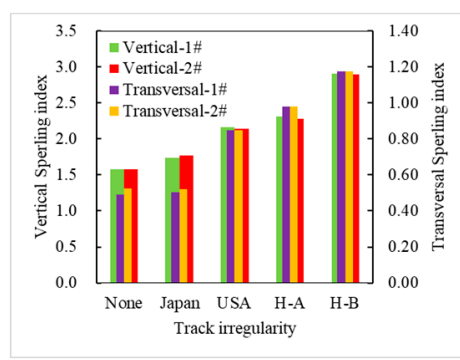

(e)

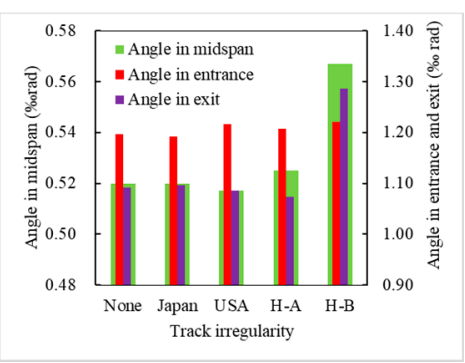

(c)

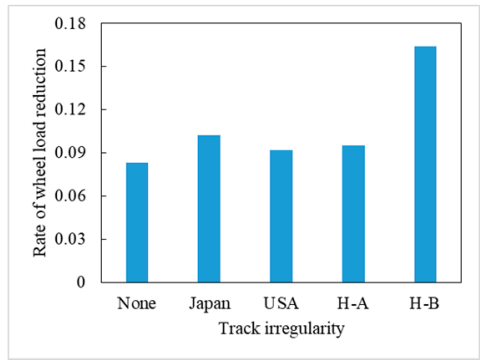

(f)

Figure 12. Responses of the bridge and the train considering differences in track irregularity-(a) bridge deflection, (b) bridge acceleration, (c) bridge angle, (d) train acceleration, (e) Sperling index, and (f) rate of wheel load reduction.

Figure $12 a-c$ show that the deformation and acceleration of the bridge increased, as the amplitude of the irregularity increased, and the vertical responses of the bridge were very sensitive to the irregularity. In the case of B-level national standard road roughness, each response had a sudden increase, and the vertical acceleration exceeded the limit value. Hence, it was necessary to control the track irregularity.

Figure $12 \mathrm{~d}-\mathrm{f}$ show that the vehicle body acceleration, Sperling index, and the rate of load reduction all increases, as the roughness amplitude increased, among which the vertical responses were quite sensitive to the roughness. When the track irregularity reached the B-level road roughness, several of the monorail vehicle responses exceeded the limit requirements, and the riding comfort was very poor. When the track irregularity was smoother than the A-level road roughness, the riding comfort could generally be guaranteed. The amplitude of the track irregularity in a monorail traffic system should be controlled within a reasonable range to meet the requirements of riding comfort and operational safety. 


\section{Improvement Measures}

According to the above analysis, the riding comfort of a straddle-type monorail could not meet the travel requirements under several operating conditions and thus required further improvements. This study proposed some improvement measures from the perspectives of the bridge parameters.

A larger vertical response, results in violent bridge vibrations, which affect the riding comfort of a straddle-type monorail. According to the above analysis, the vertical response of a bridge is mainly affected by the vertical stiffness and the load on the bridge; hence, this study attempted to reduce the coupling vibration and improve the riding comfort by increasing the stiffness of the bridge. To increase the vertical stiffness, the beam height could be increased, as shown in Figure 13a. To increase the lateral stiffness of a bridge, two methods were proposed in this study, as shown in Figure 13b,c. The first of these methods involved increasing the thickness of the cross-beams, wherein the thickness of the end cross-beams were changed from $0.78 \mathrm{~m}$ to $1.5 \mathrm{~m}$, and the thickness of the middle beam was changed from $0.25 \mathrm{~m}$ to $0.5 \mathrm{~m}$. The other method involved setting the external beams between the two track beams, wherein the thickness of the end external beams was $1.5 \mathrm{~m}$, and the thickness of the middle external beams was $0.5 \mathrm{~m}$; note that the height was set to $0.15 \mathrm{~m}$, as it was limited by the height of the track beam, and the construction of the vehicle bogie. The improvement measures are summarized in Table 9.

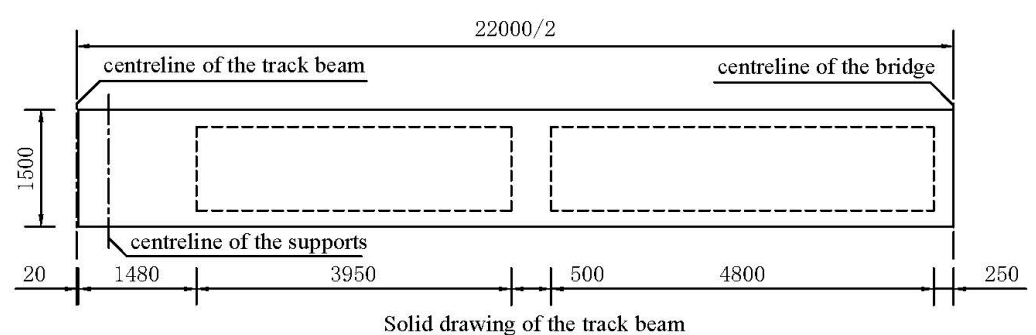

(a)

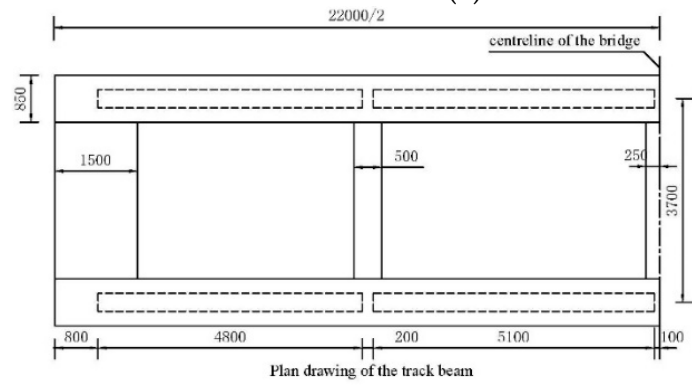

(c)

)

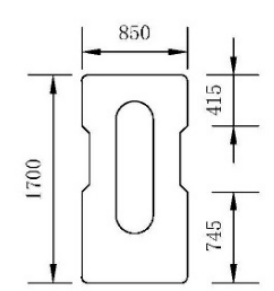

(b)

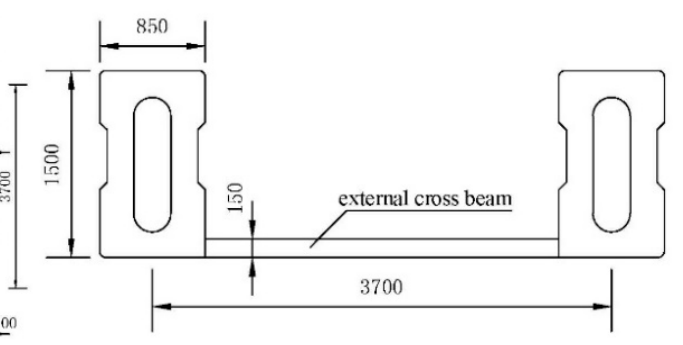

Figure 13. Improvement measures for the bridge-(a) increasing the thickness of the inner cross-beams $(\mathrm{mm}),(\mathbf{b})$ increasing the beam height $(\mathrm{mm})$, and $(\mathbf{c})$ setting external cross-beams $(\mathrm{mm})$.

Table 9. Improvement measures.

\begin{tabular}{|c|c|}
\hline Case No. & Description of the Improvement Measures \\
\hline 1 & None \\
\hline 2 & Increase the thickness of the inner cross-beams \\
\hline 3 & Set two end external cross-beams \\
\hline 4 & Set two end external cross-beams and three middle external cross-beams \\
\hline 5 & Increase the beam height to $1.7 \mathrm{~m}$ \\
\hline 6 & $\begin{array}{c}\text { Increase the beam height to } 1.7 \mathrm{~m} \text {, and increase the thickness of the inner } \\
\text { cross-beams }\end{array}$ \\
\hline
\end{tabular}

In the dynamic analysis, the running speed of the straddle-type monorail was $65 \mathrm{~km} / \mathrm{h}$, the height of the bridge pier was $7 \mathrm{~m}$, and the American six-level track irregularity and rated load were adopted. The responses of the bridge and the train under different improvement measures are shown in Figure 14. 


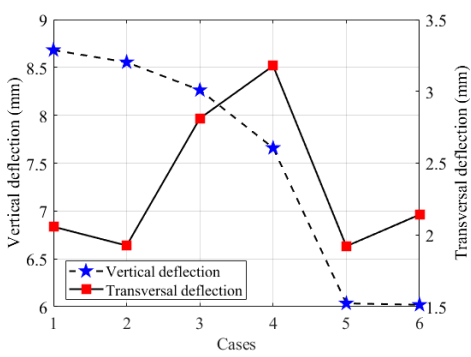

(a)

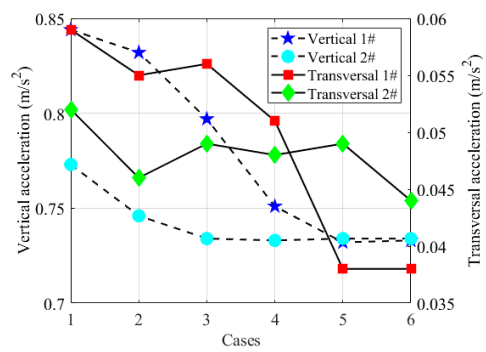

(d)

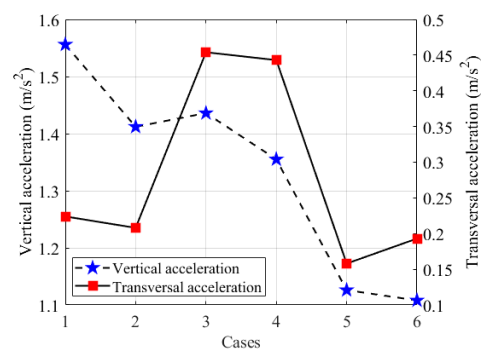

(b)

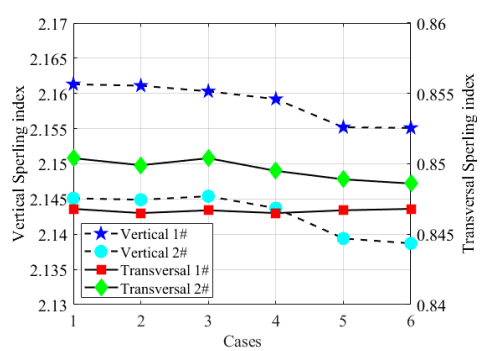

(e)

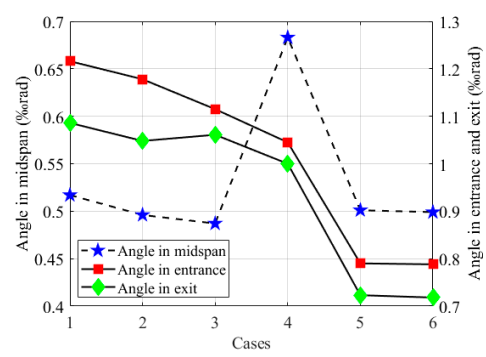

(c)

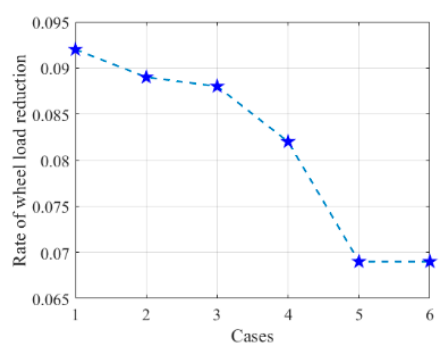

(f)

Figure 14. Responses of the bridge and the train under different improvement cases-(a) bridge deflection, (b) bridge acceleration, (c) bridge angle, (d) train acceleration, (e) Sperling index, and (f) rate of wheel load reduction.

Figure $14 \mathrm{a}-\mathrm{c}$ show that increasing the width of the inner cross-beams could reduce the deformation and midspan acceleration of the bridge to a certain extent and could substantially reduce the lateral responses of the bridge. The essence of this measure was to increase the local transverse and vertical stiffness of the bridge to weaken the bridge deformation.

When only the track beam height was increased (to $1.7 \mathrm{~m}$ ), the responses of the bridge decreased substantially, and the improvement effect was superior to that of the first method. The reason was that the increase in beam height created a larger cross-section of the track beam; hence, the vertical stiffness was improved. In addition, the section hollowing area remained the same, the section hollowing rate decreased, and the transverse stiffness was improved.

When the width of the inner beam was increased on the basis that the height of the track beam was $1.7 \mathrm{~m}$, the bridge response results were similar to that when only the beam height was increased. The reason was that the track beam had a large stiffness, and the increase in stiffness provided by the widened inner beams was not obvious, as compared to the stiffness of the track beam.

The vertical deflection, vertical acceleration, midspan torsion angle, and beam end bending angle of the bridge all decreased, whereas the transverse deformation and acceleration of the bridge increased when only two external end cross-beams were placed between the two track beams. The height of the external cross-beams could reach only $0.15 \mathrm{~m}$, the stiffness was weak, and the deformation of the cross-beam led to an increase in the track beam displacement.

When the track beam height was maintained at $1.5 \mathrm{~m}$ and two external end cross-beams and three external middle cross-beams were set between the track beams, the vertical deflection, vertical acceleration, and beam end bending angle of the bridge were improved, while the transverse deformation, transverse acceleration, and midspan torsion angle were increased. The external middle beams strengthened the connection between the two track beams, but the increase in track beam transverse responses caused by the deformation of the middle cross-beams exceeded the decrease in the response caused by the integrity of the bridge. In terms of the improvement degree of the bridge responses, measures of widening the inner cross-beams, increasing the track beam height, or a combination of the two methods were the most effective approaches.

Figure $14 \mathrm{~d}-\mathrm{f}$ indicate that in the case where the inner cross-beams were widened, the vehicle acceleration, transverse Sperling index, and the rate of wheel load reduction rate all decreased, whereas 
the vertical Sperling index did not change significantly. When only the beam height was increased, all vehicle responses were obviously reduced, and the comfort improvement effect was much better. When the inner cross-beams were widened on the basis that the track beam height was $1.7 \mathrm{~m}$, the monorail vehicle responses were almost the same as those when only the beam height increased. When the beam height was unchanged and two external end cross-beams were placed between the track beams, the vehicle acceleration and the rate of wheel load reduction decreased, whereas the Sperling index hardly improved. When the beam height was unchanged and two external end cross-beams and three external middle cross-beams were placed between the track beams, the vehicle acceleration was significantly reduced, the Sperling index and the rate of wheel load reduction decreased, and the monorail vehicle comfort was improved to a certain extent. Considering the improvement degree of the monorail vehicle responses, it was most effective to widen the internal cross-beams, increase the track beam height, or set the external end cross-beams and middle cross-beams between the track beams.

The combination of the above analysis results revealed that the most effective measures to improve the riding comfort of straddle-type monorails were to widen the inner cross-beams and increase the track beam height appropriately, which essentially increased the stiffness of the bridge.

\section{Conclusions}

To study the riding comfort of a straddle-type monorail considering the influence of the bridge structure, a model of a coupled straddle-type monorail system based on SIMPACK and ANSYS was established in this study. Since the vehicle model with 35 DOFs was established directly in SIMPACK, complicated programming was avoided, and the simulation of a moving vehicle load was more convenient. Dynamic analyses were carried out to study the influencing factors of riding comfort, and measures to improve the riding comfort from the perspective of the bridge structure were explored. For the $3 \mathrm{~m} \times 22 \mathrm{~m}$ double-track beam bridge and the four straddle-type monorail trains studied in this study, the following main conclusions could be drawn:

1. The bridge acceleration was positively correlated with speed, whereas the bridge deflection had little correlation with speed. The acceleration and Sperling indices of the vehicle increased with increasing speed, which meant that the riding comfort became worse. Speeds below $75 \mathrm{~km} / \mathrm{h}$ could ensure good operation conditions. In all cases, the maximum vertical and lateral Sperling indices were 2.512 and 0.933 , respectively; the lateral comfort of the vehicle was better due to the symmetrical horizontal wheels.

2. Taking the linear stiffness of the pier as the index of the bridge pier height, the influence of different pier heights on riding comfort is analyzed. The results showed that the vehicle-bridge response generally decreased as the linear stiffness of the pier increased; when the stiffness of the pier was low, the flexibility of the bridge was high. The lateral dynamic responses of the vehicle and bridge were very sensitive to changes in the linear stiffness of the pier.

3. When the amplitude of the irregularity reached the Chinese national B-level road roughness, the vertical Sperling index was 2.906, which indicated poor riding comfort. In practice, the surface roughness of the track beam should be strictly controlled. It should be smoother than Chinese national A-level road roughness, and the range should be between $-8 \mathrm{~mm}$ and $8 \mathrm{~mm}$. Based on a large number of actual measurements on the track beam surface roughness of straddle-type monorails, a roughness index similar to the International Roughness Index (IRI) could be proposed, and its threshold could be specified to provide guidance for related projects.

4. The proposed measures that increased the stiffness of the track beam were effective for the improvement of riding comfort, such as increasing the thickness of the inner cross-beams and increasing the height of the track beams.

Author Contributions: The authors contributed equally to this work. Q.G. and K.C. conceived and prepared the original draft. K.C. and Z.L. provided analysis tools. Q.G. and Y.L. analyzed the data. Z.L. and Y.L. reviewed the manuscript. All authors have read and agreed to the published version of the manuscript. 
Funding: This research was funded by the National Natural Science Foundation of China (grant No. 51778194), the China Postdoctoral Science Foundation (grant No. 2017M621282), and the Fundamental Research Funds for the Central Universities (grant No. HIT. NSRIF. 2019056).

Conflicts of Interest: The authors declare no conflicts of interest regarding the publication of this manuscript.

\section{References}

1. Pak, P.S.; Tsuji, K.; Suzuki, Y. Comprehensive evaluation of new urban transportation systems by AHP. Int. J. Syst. Sci. 1987, 18, 1179-1190. [CrossRef]

2. Ishikawa, K. Straddle-type monorail as a leading urban transport system for the 21st century. Hitachi Rev. 2019, 48, 149-152.

3. Timan, P.E. Why Monorail Systems Provide a Great Solution for Metropolitan Areas. Urban Rail Transit. 2015, 1, 13-25. [CrossRef]

4. Kikuchi, S.; Onaka, A. Monorail development and application in Japan. J. Adv. Transport. 1988, $22,17-38$. [CrossRef]

5. Kato, M.; Yamazaki, K. Straddle-type monorail systems with driverless train operation system. Hitachi Rev. 2019, 53, 25-29.

6. Tsang, M.; He, E. Straddle Monorail-Implementation Challenges. In Proceedings of the 16th International Conference on Automated People Movers and Automated Transit Systems, Tampa, FL, USA; 2018.

7. Chu, K.H.; Garg, V.K.; Wiriyachai, A. Dynamic Interaction of Railway Train and Bridges. Veh. Syst. Dyn. 1980, 9, 207-236. [CrossRef]

8. Chu, K.H.; Garg, V.K.; Dhar, C.L. Railway-Bridge Impact: Simplified Train and Bridge Model. J. Struct. 1979, 105, 1824-1844.

9. Wiriyachai, A.; Chu, K.H.; Garg, V.K. Bridge Impact Due to Wheel and Track Irregularities. J. Eng. Mech. 1982, 108, 648-666.

10. Wang, T.L.; Chu, K.H. Railway Bridge/Vehicle Interaction Studies with New Vehicle Model. J. Struct. Eng. 1991, 117, 2099-2116. [CrossRef]

11. Wang, T.L. Ramp/Bridge Interface in Railway Prestressed Concrete Bridge. J. Struct. Eng. 1990, 116, $1648-1659$. [CrossRef]

12. Wang, T.L. Impact in a Railway Truss Bridge. Comput. Struct. 1993, 49, 1045-1054. [CrossRef]

13. Vanbogaert, P. Dynamic response of trains crossing large span double-track bridges. J. Constr. Steel. Res. 1993, 24, 57-74. [CrossRef]

14. Eom, B.G.; Lee, H.S. Assessment of running safety of railway vehicles using multibody dynamics. Int. J. Precis. Eng. Manuf. 2010, 2, 315-320. [CrossRef]

15. Miyamoto, T.; Ishida, H.; Matsuo, M. Running safety of railway vehicles as earthquake occurs. Quart. Rep. 1997, 38, 117-122.

16. Yang, Y.B.; Wu, Y.S. Dynamic Stability of Trains Moving over Bridges Shaken by Earthquakes. J. Sound. Vib. 2002, 258, 64-94. [CrossRef]

17. Fryba, L. A rough assessment of railway bridges for high speed trains. Eng. Struct. 2001, 23, 548-556. [CrossRef]

18. Lee, C.H.; Kim, C.W. Dynamic response analysis of monorail bridges under moving trains and riding comfort of trains. Eng. Struct. 2005, 27, 1999-2013. [CrossRef]

19. Naeimi, M.; Tatari, M.; Esmaeilzadeh, A.; Mehrali, M. Dynamic interaction of the monorail-bridge system using a combined finite element multibody-based model. J. Multi-Body Dyn. 2015, 229, 132-151. [CrossRef]

20. Yau, J.D.; Yang, Y.B.; Kuo, S.R. Impact response of high-speed rail bridges and riding comfort of rail cars. Eng. Struct. 1999, 21, 836-844. [CrossRef]

21. Carlbom, P.F. Combining MBS with FEM for Rail Vehicle Dynamics Analysis. Multibody Syst. Dyn. 2001, 3, $291-300$. [CrossRef]

22. Zhang, S.Y.; Liu, Y. Damage detection of bridges monitored within one cluster based on the residual between the cumulative distribution functions of strain monitoring data. Struct Health Monit. 2020. [CrossRef]

23. Gao, Q.F.; Dong, Z.L.; Cui, K.M.; Liu, C.G.; Liu, Y. Fatigue performance of profiled steel sheeting-concrete bridge decks subjected to vehicular loads. Eng. Struct. 2020, 213, 110558. [CrossRef] 
24. Gao, Q.F.; Cui, K.M.; Li, J.; Guo, B.Q.; Liu, Y. Optimal layout of sensors in large-span cable-stayed bridges subjected to moving vehicular loads. Int. J. Distrib. Sens. Netw. 2020. [CrossRef]

25. Yildiz, A.S.; Sivrioglu, S. Semi-active Vibration Control of Lateral and Rolling Motions for a Straddle Type Monorail Vehicle. IFAC-PapersOnline 2016, 49, 279-284. [CrossRef]

26. Ivanchenko, I.I. Substructure method in high-speed monorail dynamic problems. Mech. Solids 2008, 43, 925-938. [CrossRef]

27. Rybak, S.A.; Makhortykh, S.A.; Kostarev, S.A. Theoretical and experimental study of vibration, generated by monorail trains. J. Acoust. Soc. Am. 2002, 112, 2247-2248. [CrossRef]

28. Goda, K.; Nishigaito, T. A curving simulation for a monorail car Railroad Conference. In Proceedings of the 2000 ASME/IEEEJoint, Newark, NJ, USA, 6 April 2000; pp. 171-177.

29. Goda, K.; Nishigaito, T.; Hiraishi, M.; Iwasaki, K. Response Analysis caused by Track Irregularity for a Monorail Car: A Study for Dynamic Model Considering the Direction of Tire Force. Trans. Jpn. Soc. Mech. Eng. Part C 1999, 65, 3546-3552. [CrossRef]

30. Goda, K.; Nishigaito, T.; Hiraishi, M.; Iwasaki, K. Improving curving performance for articulated-type small monorail car. Trans. Jpn. Soc. Mech. Eng. Part C 2002, 68, 2410-2417. [CrossRef]

31. Zheng, K.F. Dynamics Simulation Analysis and Optimization of Straddle-Type Monorail. Ph.D. Thesis, Chongqing JiaoTong University, Chongqing, China, 2010.

32. Li, N. Simulation and Evaluation of the Dynamic Performance of Straddle-Type Monorail Vehicle System. Ph.D. Thesis, Chongqing JiaoTong university, Chongqing, China, 2011.

33. Shi, Z.; Pu, Q.H.; Gao, Y.F.; Xia, Z.G. Experimental study on dynamic characteristics of straddle-type monorail in Chongqing. Vib. Impact. 2008, 12, 101-106.

34. Bao, Y.L.; Li, Y.L.; Ding, J.J. A case study of dynamic response analysis and safety assessment for a suspended monorail system. Int. J. Env. Res. Public Health 2016, 13, 1121. [CrossRef]

35. Qiao, Z. Research on the Dynamic Behavior of Straddle-Type Monorail Vehicle-Track Beam Coupling System. Ph.D. Thesis, Beijing JiaoTong University, Beijing, China, 2016.

36. Wang, H.D.; Wang, W.; Dai, H.Z. Basic Principles of Finite Element Method; Harbin Institute of Technology Press: Harbin, China, 2016; pp. 1-4.

37. ISO 8608:2016. Mechanical Vibration-Road Surface Profiles-Reporting of Measured Data; The International Organization for Standardization: Lodon, UK, 2016.

38. Garg, V.K.; Dukkipati, R.V. Dynamics of Railway Vehicle Systems; Academic Press: Ontario, Canada, 1984.

39. Miao, B.R.; Xiang, H.; Fu, X.T. Basic Course of SIMPACK Dynamic Analysis; Southwest Jiaotong University Press: Chengdu, China, 2008; pp. 13-33.

40. Lee, C.H.; Kawatani, M.; Kim, C.W. Dynamic response of a monorail steel bridge under a moving train. J. Sound. Vib. 2006, 294, 562-579. [CrossRef]

41. Wang, X.M. ANSYS Numerical Analysis of Engineering Structure; China Communications Press: Beijing, China, 2017; pp. 514-517.

42. TB 10002-2017. Code for Design on Railway Bridge and Culvert, Beijing, China, 2017.

43. GB 50458-2008. Code for Design of Straddle Monorail Transit, Beijing, China, 2008.

44. GB 5599-85. Standard for Dynamic Performance Evaluation and Test Identification of Railway Vehicles, Beijing, China, 1985.

45. TB/T-2360-93. Evaluation Method and Standard for Railway Locomotive Dynamics Test, Beijing, China, 1993.

(C) 2020 by the authors. Licensee MDPI, Basel, Switzerland. This article is an open access article distributed under the terms and conditions of the Creative Commons Attribution (CC BY) license (http://creativecommons.org/licenses/by/4.0/). 